\title{
Association between Therapeutic Adherence and the Profile of Patients with Resistant Hypertension
}

\author{
Luciana Baltazar da Silveira de Araújo ${ }^{1 \oplus}$ and Roque Aras Junior ${ }^{2}$ \\ Faculdade de Medicina da Bahia, ${ }^{1}$ Salvador, BA-Brazil \\ Hospital Universitário Professor Edgar Santos, ${ }^{2}$ Salvador, BA-Brazil
}

\section{Abstract}

Background: Resistant hypertension (RH) consists of increased blood pressure (BP) despite the use of 3 or more antihypertensives or BP control only when is use of 4 or more antihypertensives. It is fundamental to exclude pseudoresistance, which can be attributed to poor therapeutic adherence. Adherence evaluation, generally by the Morisky-Grenn test, is important because, when appropriate, it is associated with fewer cardiovascular complications and better BP control.

Objectives: To evaluate the adherence of patients with RH and to investigate its relation with epidemiological, anthropometric and clinical characteristics, as well as to estimate the prevalence of pseudoresistance and to outline strategies to improve adherence.

Methods: Retrospective observational cohort from an interview with patients followed at an outpatient clinic for RH. Therapeutic adherence, demographic, anthropometric data, cardiovascular risk factors, comorbidities, complementary exams and BP level were collected. One-way ANOVA and Student's t-tests were used for normal variables, and the Kruskal-Wallis and Mann-Whitney tests were used for non-normal tests. Categorical variables were compared using the Chi-Square test. We considered a 5\% significance level in all tests.

Results: 217 individuals were included. Of these, 17\% had poor adherence. Epidemiological and clinical characteristics, complications, comorbidities, BP level or drugs used were statistically insignificant between groups. The poor adherence group used significantly more drugs $(p=0.0313)$ and $28 \%$ of pseudoresistance was estimated.

Conclusions: Most of the individuals presented good therapeutic adherence by the Morisky test. Only the number of antihypertensive drugs had a statistically significant influence on adherence, while the epidemiological, anthropometric and clinical characteristics were statistically insignificant. (Int J Cardiovasc Sci. 2020; 33(2):121-130)

Keywords: Hypertension; Antihypertensive Agents/pharmacology; Antihypertensive Agents/therapeutic use; Blood Pressure Determination; Drug Resistance; Life Style; Prognosis.

\section{Introduction}

Resistant hypertension ( $\mathrm{RH})$ is defined as uncontrolled blood pressure (BP) despite the use of three or more antihypertensives at the maximum tolerated doses (including, preferably, thiazide diuretics) or as BP control only when in use of four or more drugs. ${ }^{1-3}$
In the investigation of $\mathrm{RH}$, it is always necessary to exclude the possibility of pseudoresistance, since the differentiation between true and apparent $\mathrm{RH}$ determines specific therapeutic measures. ${ }^{1,3}$ Factors related to pseudoresistance include white coat hypertension, poor BP measurement technique, inadequate therapeutic regimen and/or poor therapeutic adherence, ${ }^{1-3}$ which 
is an important and challenging cause, since studies indicate that $50-80 \%$ of patients with systemic arterial hypertension (SAH) do not adhere to the medications. ${ }^{1}$

The RH treatment - as well as that of non-resistant hypertension - is based on non-medication and medication measures. Drug therapy consists of the association of antihypertensives with action on the main pathophysiological mechanisms of BP elevation. Thus, a diuretic, renin-angiotensin-aldosterone system inhibitor - ACE inhibitor (ACEI) or angiotensin receptor blocker (ARB) - and a calcium channel blocker (CCB) should be initially prescribed at full tolerated doses and adequate intervals. ${ }^{1,3}$

Studies indicate that, with good adherence to treatment, there is better clinical evolution regarding minimizing and/or postponing cardiovascular complications, in addition to more effective control of BP. ${ }^{1,3}$ Therefore, failure to adhere to the proposed therapy, being one of the main obstacles to the control of $\mathrm{BP},{ }^{3,4}$ contributes to higher morbidity and mortality.

There are several strategies for the detection and evaluation of therapeutic adherence, but without any consensus. ${ }^{5}$ Questionnaires based on patient reports, despite low sensitivity and accuracy, are the most commonly used method due to simplicity and low cost. ${ }^{4,5}$ Of these, the most used in Brazil ${ }^{4}$ is the Morisky-Grenn test (TMG), ${ }^{6}$ composed of questions that can easily be inserted in the medical interview..$^{5,7}$ In addition, it has been shown to be useful for identifying patients that either adhere or not to the treatment, ${ }^{5}$ with sensitivity of $43.6 \%$ and specificity of $81 \%{ }^{4}$

In view of the high prevalence of poor adherence to antihypertensive treatment and considering the impact on morbidity and mortality due to impaired $\mathrm{BP}$ control, it is important to analyze this aspect in the follow-up of patients with SAH. Special attention is paid to individuals with $\mathrm{RH}$, since they require more antihypertensive agents, which may contribute to poor adherence to treatment.

Therefore, the main objective of the study is to determine the degree of therapeutic adherence of patients with $\mathrm{RH}$ followed in a referral clinic through the Morisky scale and to evaluate its relationship with the epidemiological, anthropometric and clinical profile of these patients, as well as with the cardiovascular outcomes, complications and comorbidities associated with SAH. Secondary objectives are to estimate the prevalence of pseudoresistance and to devise strategies to improve therapeutic adherence.

\section{Methods}

\section{Study design and sample}

The study was an observational retrospective cohort based on interview with patients. The convenience sample included individuals aged 18 years and older, followed between 2012 and 2017, at the service of Severe Hypertensive Cardiovascular Disease of Ambulatório José Maria de Magalhães Neto Ambulatory, belonging to Complexo Hospitalar Universitário Professor Edgard Santos (Complexo-HUPES), Universidade Federal da Bahia (UFBA), who accepted to participate in the study by providing written Informed Consent. There were no exclusion criteria.

\section{Analyzed variables}

For all patients included in the study, a standardized questionnaire was used to collect data on therapeutic adherence through the Morisky-Grenn test, as well as epidemiological data (sex, age, education and ethnicity), anthropometric data (body mass index [BMI], systolic BP and diastolic BP) and clinical data (time of diagnosis of hypertension, time of followup in the outpatient clinic, alcoholism, current and previous smoking, antihypertensive drugs in use, comorbidities and complications - prior acute myocardial infarction [AMI], prior stroke, diabetes mellitus [DM], dyslipidemia and metabolic syndrome). In addition, data from routine laboratory exams and 24-hour ambulatory blood pressure monitoring (ABPM) were evaluated. BP measurement was performed according to the recommendations of the Brazilian Society of Cardiology. ${ }^{1}$

Patients were stratified according to the MoriskyGrenn test in having good therapeutic adherence (6 to 8 points) or poor therapeutic adherence (5 points or less). In both subgroups, the epidemiological, anthropometric and clinical profiles, presence of comorbidities and complications, blood pressure levels and antihypertensive medications in use were analyzed.

\section{Statistical analysis}

The parameters studied were evaluated in terms of the type of distribution using the D'Agostino-Pearson statistical test. The data collected are presented as mean and standard deviation (mean $\pm \mathrm{SD}$ ) for continuous variables with normal distribution and as median and interquartile range for non-normal continuous variables. 
Categorical variables are presented by absolute numbers and percentages.

The patients were compared according to the degree of therapeutic adherence by the one-way ANOVA test for variables with normal distribution, and KruskalWallis, followed by Dunn's post-test, when the variables were not normally distributed. Categorical variables were also compared by the distribution of events using Fisher's or Chi-Square test. Comparison between two groups was done with unpaired Student's t-test (with Welch's correction when necessary) when they presented normal distribution, or with the nonparametric MannWhitney test for variables without normal distribution. A significant value of $\mathrm{p}<0.05$ was considered. Prism software version 7.04 (GraphPad Software, Inc., San Diego, CA, USA) was used.

\section{Ethical considerations}

This project is an addendum to the project "Clinical and Metabolic Evaluation in Resistant Systemic Arterial Hypertension", inserting itself in its specific objectives. The project was approved by the Ethics and Research Committee of Hospital Ana Nery, protocol number 138371 , on $11 / 05 / 2012$. All patients enrolled in the study signed an Informed Consent.

\section{Results}

The study included 216 individuals, who were classified according to the Morisky Therapeutic Adherence Scale. Of these, 136 (83\%) had good therapeutic adherence and $28(17 \%)$ had poor adherence. The percentage of each test response can be seen in figure 1.

The epidemiological, anthropometric and clinical characteristics of these individuals can be seen in table 1 , while the prevalence of comorbidities and complications can be seen in table 2 .

By comparing the epidemiological and clinical characteristics between the groups divided according to the degree of therapeutic adherence, there is no statistical significance for the variables considered (table 1), similarly for complications and comorbidities (table 2).

In the group with good therapeutic adherence, $37.83 \%$ of the individuals had controlled BP (normal or prehypertension), whereas of the individuals with poor adherence, $26.92 \%$ had controlled BP. Despite the differences between the groups, there was no statistical significance $(p=0.2921)$ (table 3$)$.

The antihypertensive drugs most commonly used by the individuals in the sample were amlodipine (68.91\%) [CCB], losartan (66.37\%) [ARB], hydrochlorothiazide $(47.7 \%)$, chlorthalidone $(44.34 \%)$ [thiazide diuretics] and

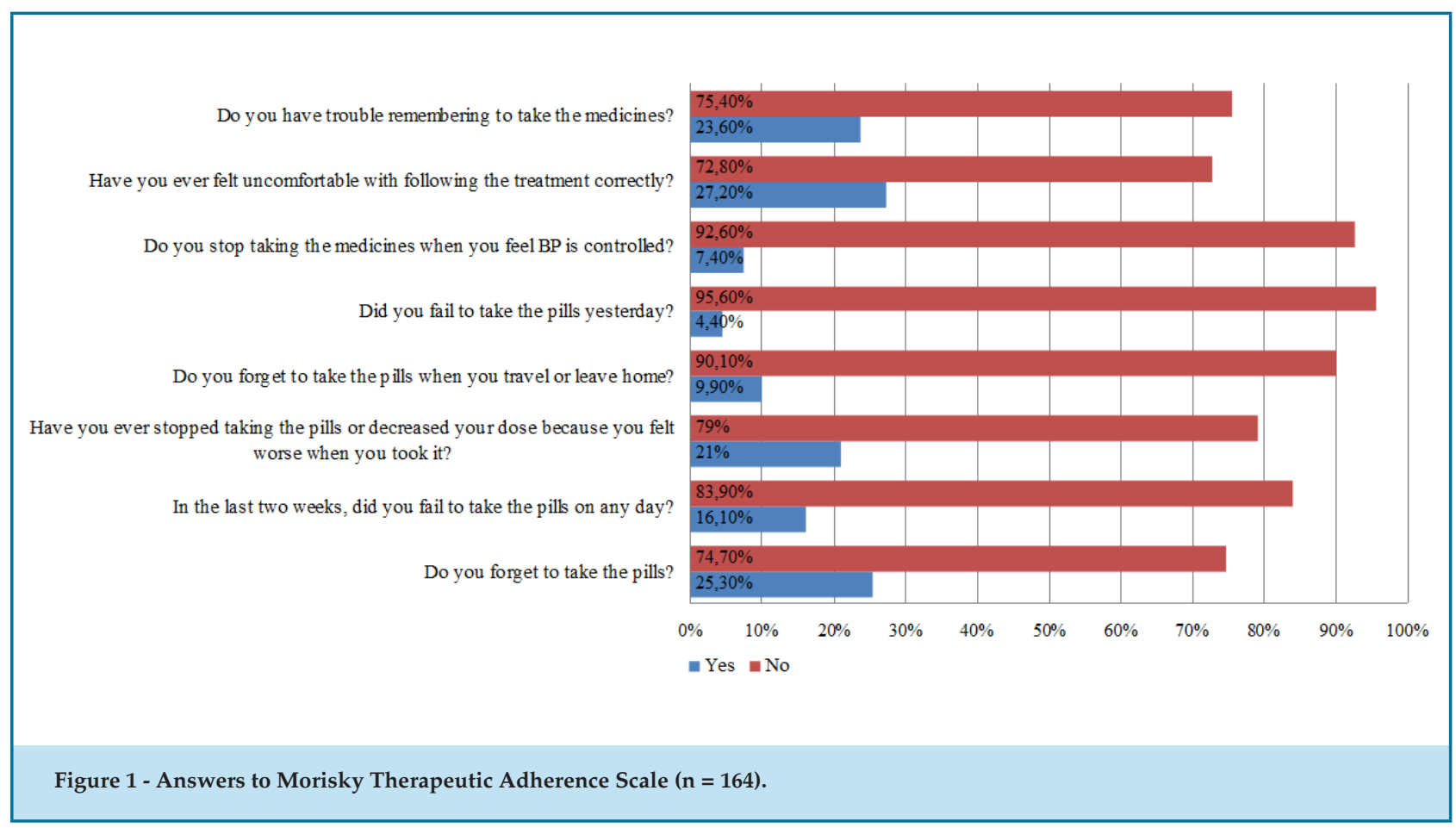


Table 1 - Epidemiological, anthropometric and clinical profile

\begin{tabular}{|c|c|c|c|c|}
\hline \multirow{2}{*}{ Variables } & \multicolumn{4}{|c|}{ Frequency $(\%) /$ mean $(\mathrm{SD})$} \\
\hline & General & Good adherence & Poor adherence & $\mathrm{p}$ value $(<0.05)$ \\
\hline Gender & $(\mathrm{n}=216)$ & $(\mathrm{n}=135)$ & $(\mathrm{n}=28)$ & \\
\hline Female & $73.14 \%$ & $75.5 \%$ & $71.42 \%$ & 0.6494 \\
\hline Male & $26.85 \%$ & $24.4 \%$ & $28.58 \%$ & \\
\hline Age (years) & $\begin{array}{c}(\mathrm{n}=212) \\
63.49(11.57)\end{array}$ & $\begin{array}{c}(\mathrm{n}=127) \\
63.91(11.44)\end{array}$ & $\begin{array}{c}(\mathrm{n}=25) \\
62(55-69.5)\end{array}$ & 0.4292 \\
\hline Education & $(\mathrm{n}=212)$ & $(\mathrm{n}=134)$ & $(\mathrm{n}=28)$ & \\
\hline Illiterate & $11.3 \%$ & $11.19 \%$ & $14.28 \%$ & \\
\hline Incomplete primary school & $13.6 \%$ & $13.43 \%$ & $17.85 \%$ & \\
\hline Complete primary school & $8.9 \%$ & $8.95 \%$ & $10.71 \%$ & \\
\hline Incomplete middle school & $30.6 \%$ & $28.35 \%$ & $17.85 \%$ & \\
\hline Complete middle school & $5.1 \%$ & $5.22 \%$ & $3.57 \%$ & 0.6077 \\
\hline Incomplete high school & $7.5 \%$ & $6.71 \%$ & $17.85 \%$ & \\
\hline Complete high school & $18.8 \%$ & $23.88 \%$ & $10.71 \%$ & \\
\hline Vocational training & $1.4 \%$ & $0 \%$ & $7.14 \%$ & \\
\hline $\begin{array}{l}\text { Incomplete higher } \\
\text { education }\end{array}$ & $0.4 \%$ & $0 \%$ & $0 \%$ & \\
\hline Graduated & $1.8 \%$ & $2.23 \%$ & $0 \%$ & \\
\hline Ethnicity & $(\mathrm{n}=215)$ & $(\mathrm{n}=134)$ & $(\mathrm{n}=28)$ & \\
\hline White & $8.37 \%$ & $7.46 \%$ & $14.28 \%$ & 04479 \\
\hline Black & $53.48 \%$ & $55.22 \%$ & $50 \%$ & 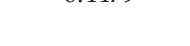 \\
\hline Brown & $38.13 \%$ & $36.56 \%$ & $35.71 \%$ & \\
\hline BMI $\left(\mathrm{kg} / \mathrm{m}^{2}\right)$ & $(\mathrm{n}=165)$ & $(\mathrm{n}=118)$ & $(n=26)$ & \\
\hline Low weight $(<18,5)$ & $2 \%$ & $1.69 \%$ & $0 \%$ & \\
\hline Ideal $(18,5-24,9)$ & $13 \%$ & $12.71 \%$ & $15.38 \%$ & \\
\hline Overweight (25 - 29.9) & $35 \%$ & $34.74 \%$ & $23.07 \%$ & 0.3403 \\
\hline Obesity I $(30-34,5)$ & $34 \%$ & $34.74 \%$ & $34.61 \%$ & \\
\hline Obesity II $(35-39,9)$ & $12 \%$ & $10.16 \%$ & $19.23 \%$ & \\
\hline Obesity III (> 40) & $5 \%$ & $5.93 \%$ & $7.69 \%$ & \\
\hline Abdominal circumference $(\mathrm{cm})$ & $(\mathrm{n}=136)$ & $(\mathrm{n}=96)$ & $(\mathrm{n}=23)$ & \\
\hline Normal $(\widehat{\delta} \leq 102 ;$ ㅇ $\leq 88)$ & $22 \%$ & $21.87 \%$ & $21.73 \%$ & 0.9888 \\
\hline Increased $(\widehat{\partial}>102 ;$ ㅇ $>88)$ & $77 \%$ & $78.12 \%$ & $78.26 \%$ & \\
\hline $\begin{array}{l}\text { Systolic blood pressure } \\
(\mathrm{mmHg})\end{array}$ & $\begin{array}{c}(\mathrm{n}=160) \\
149.5(133-166.8)\end{array}$ & $\begin{array}{c}(\mathrm{n}=111) \\
149.5(130-166)\end{array}$ & $\begin{array}{c}(\mathrm{n}=26) \\
152.7(26.91)\end{array}$ & 0.6893 \\
\hline $\begin{array}{l}\text { Diastolic blood pressure } \\
(\mathrm{mmHg})\end{array}$ & $\begin{array}{c}(\mathrm{n}=160) \\
88(77-100.4)\end{array}$ & $\begin{array}{c}(\mathrm{n}=111) \\
87(77-98.88)\end{array}$ & $\begin{array}{c}(\mathrm{n}=26) \\
90(16.99)\end{array}$ & 0.6673 \\
\hline
\end{tabular}




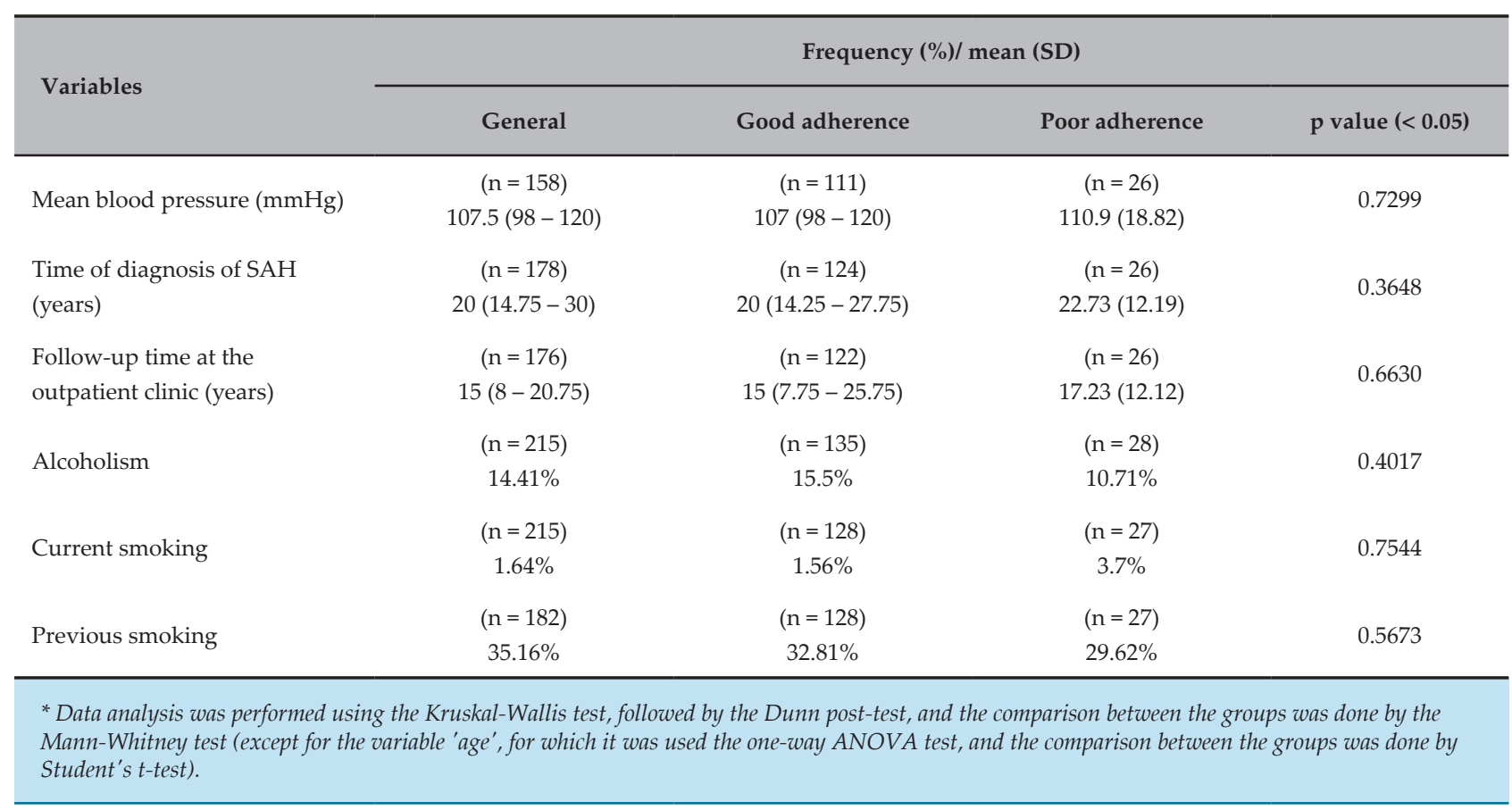

Table 2 - Comorbidities and complications

\begin{tabular}{|c|c|c|c|c|}
\hline \multirow{2}{*}{ Variables } & \multicolumn{4}{|c|}{ Frequency (\%) } \\
\hline & General & Good adherence & Poor adherence & p value $(<0.05)$ \\
\hline Previous AMI & $\begin{array}{c}18.5 \% \\
(\mathrm{n}=178)\end{array}$ & $\begin{array}{c}17.74 \% \\
(\mathrm{n}=124)\end{array}$ & $\begin{array}{l}19.23 \% \\
(n=26)\end{array}$ & 0.8586 \\
\hline Previous stroke & $\begin{array}{c}21.6 \% \\
(n=180)\end{array}$ & $\begin{array}{c}19.53 \% \\
(\mathrm{n}=128)\end{array}$ & $\begin{array}{c}36 \% \\
(\mathrm{n}=25)\end{array}$ & 0.6016 \\
\hline $\mathrm{DM}$ & $\begin{array}{c}43.95 \% \\
(\mathrm{n}=182)\end{array}$ & $\begin{array}{c}40.62 \% \\
(n=128)\end{array}$ & $\begin{array}{l}44.44 \% \\
(\mathrm{n}=27)\end{array}$ & 0.8587 \\
\hline Dyslipidemia & $\begin{array}{c}95.6 \% \\
(n=162)\end{array}$ & $\begin{array}{c}93.04 \% \\
(\mathrm{n}=115)\end{array}$ & $\begin{array}{c}100 \% \\
(\mathrm{n}=22)\end{array}$ & 0.2052 \\
\hline Metabolic syndrome & $\begin{array}{c}57.4 \% \\
(\mathrm{n}=162)\end{array}$ & $\begin{array}{c}53.04 \% \\
(\mathrm{n}=115)\end{array}$ & $\begin{array}{c}66.6 \% \\
(\mathrm{n}=24)\end{array}$ & 0.2249 \\
\hline
\end{tabular}

spironolactone (42.86\%) [potassium sparing diuretic]. The distribution of the use of these drugs according to each group can be seen in figure 2, which shows that there was no statistical difference between the groups concerning the drugs used. Regarding the use of the thiazide diuretic $+\mathrm{ACE} / \mathrm{ARB}+\mathrm{CCB}$ combination, recommended as initial therapy for patients with $\mathrm{RH}$, it was found to be used by $68.8 \%$ of individuals with good adherence and $72 \%$ of those with poor adherence, with no difference between groups $(\mathrm{p}=0.7534)$. Most of the individuals in both groups used 4 or 5 medications (figure 3). However, the group that had poor therapeutic 
Table 3 - Classification of blood pressure

\begin{tabular}{|c|c|c|c|}
\hline \multirow{2}{*}{ Classification of BP $(\mathrm{mmHg})$} & \multicolumn{2}{|c|}{ Frequency (\%) } & \multirow{2}{*}{$\mathrm{p}$ value $(<0.05)$} \\
\hline & Good adherence $(n=111)$ & Poor adherence $(n=26)$ & \\
\hline Normal $(\mathrm{SBP} \leq 120 ; \mathrm{DBP} \leq 80)$ & $10.81 \%$ & $7.69 \%$ & \\
\hline Pre-hypertension (SBP 121 - 139; DBP 81 - 89) & $27.02 \%$ & $19.23 \%$ & \\
\hline SAH stage 1 (SBP 140 - 159; DBP 90 - 99) & $23.42 \%$ & $34.61 \%$ & 0.2921 \\
\hline SAH stage 2 (SBP 160 - 179; DBP 100 - 109) & $24.32 \%$ & $19.23 \%$ & \\
\hline SAH stage $3(\mathrm{SBP} \geq 180 ; \mathrm{DBP} \geq 110)$ & $14.41 \%$ & $19.23 \%$ & \\
\hline
\end{tabular}

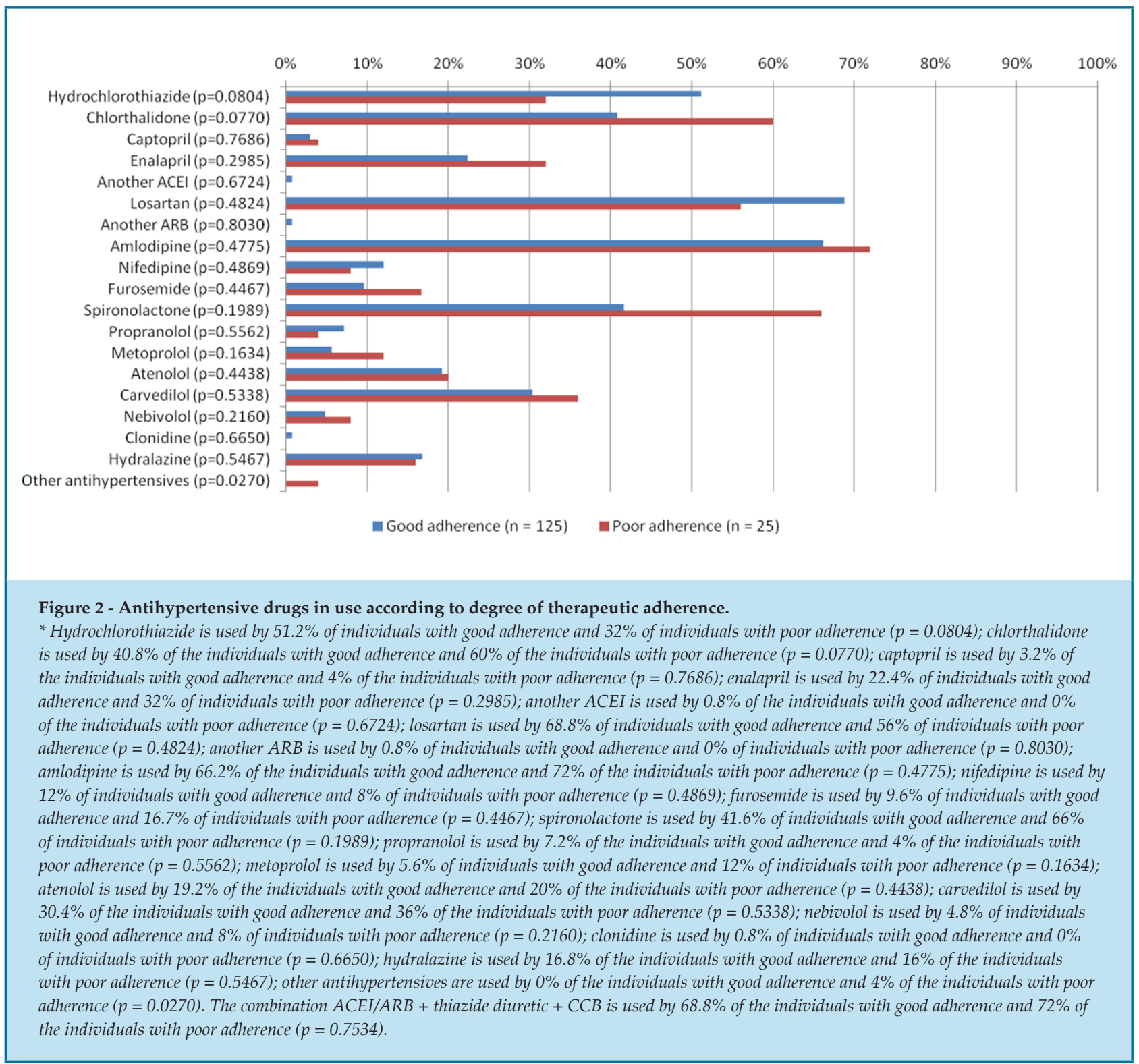


adherence used, on average, a larger number, with statistical significance $(p=0.0313)$.

Considering the need to exclude pseudoresistance for the diagnosis of true $\mathrm{RH}$, it is estimated that 43 $(19.9 \%)$ of the patients attending the outpatient clinic presented pseudoresistance, reported through the Morisky test (low adherence), inadequate therapeutic regimen (no inclusion of thiazide diuretic in the scheme) and ABPM (white coat hypertension). Thus, excluding pseudoresistance and considering the criteria for the definition of $\mathrm{RH}$ (uncontrolled BP despite the use of 3 or more antihypertensives - one of them being a thiazide diuretic - or BP control only when in use of 4 or more antihypertensives), 108 (50\%) individuals attending the outpatient clinic presented true $\mathrm{RH}$. In addition, 36 (16.6\%) individuals at the outpatient clinic (33\% of patients with true $\mathrm{RH}$ ) had refractory arterial hypertension (BP uncontrolled despite the use of 5 or more antihypertensives, including a thiazide diuretic).

\section{Discussion}

The prevalence of good therapeutic adherence found in this study (83\%) was similar to that found in the ReHOT study, ${ }^{8}$ which was approximately $80 \%$, and that found by Garg et al., ${ }^{9}$ where it was $84 \%$. However, other studies show lower rates of good adherence, such as $31.3 \%$ found by Jesus et al., ${ }^{10} 51.0 \%$ found by Bloch et al., ${ }^{11}$ and $31.2 \%$ found by Prado-Jr , et al. ${ }^{12}$ The relatively high rate of good therapeutic adherence in this study can be explained by the fact that patients are followed up at a reference outpatient clinic for Resistant Arterial Hypertension, so more attention is possibly given to the issue of adherence.

An analysis of the answers given by the patients in the Morisky test reveals that the main affirmative answer was about the discomfort of correctly following the proposed therapy $(27.2 \%)$. This provides evidence of the need to ensure that the patient has understood the importance of using medications to control BP. The second and third most prevalent responses were, respectively, about forgetting to take the medications $(25.3 \%)$ and having difficulty remembering to take the medications (23.6\%). Faced with this reality, it is fundamental to draw together patient and family strategies to help patients remember to take their medications. Another response with considerable prevalence was about discontinuing the use or reducing the dose of medications because of feeling worse (21\%). At all appointments, it is the physician's responsibility to ask patients about any adverse effects and discomfort with the use of the medications in order to, if necessary, change or make dose adjustments, thus avoiding that the patient does so improperly.

Literature shows that different factors may contribute to poor therapeutic adherence of hypertensive patients, such as gender, age, education, ethnicity, smoking, alcohol consumption, comorbidities and duration of

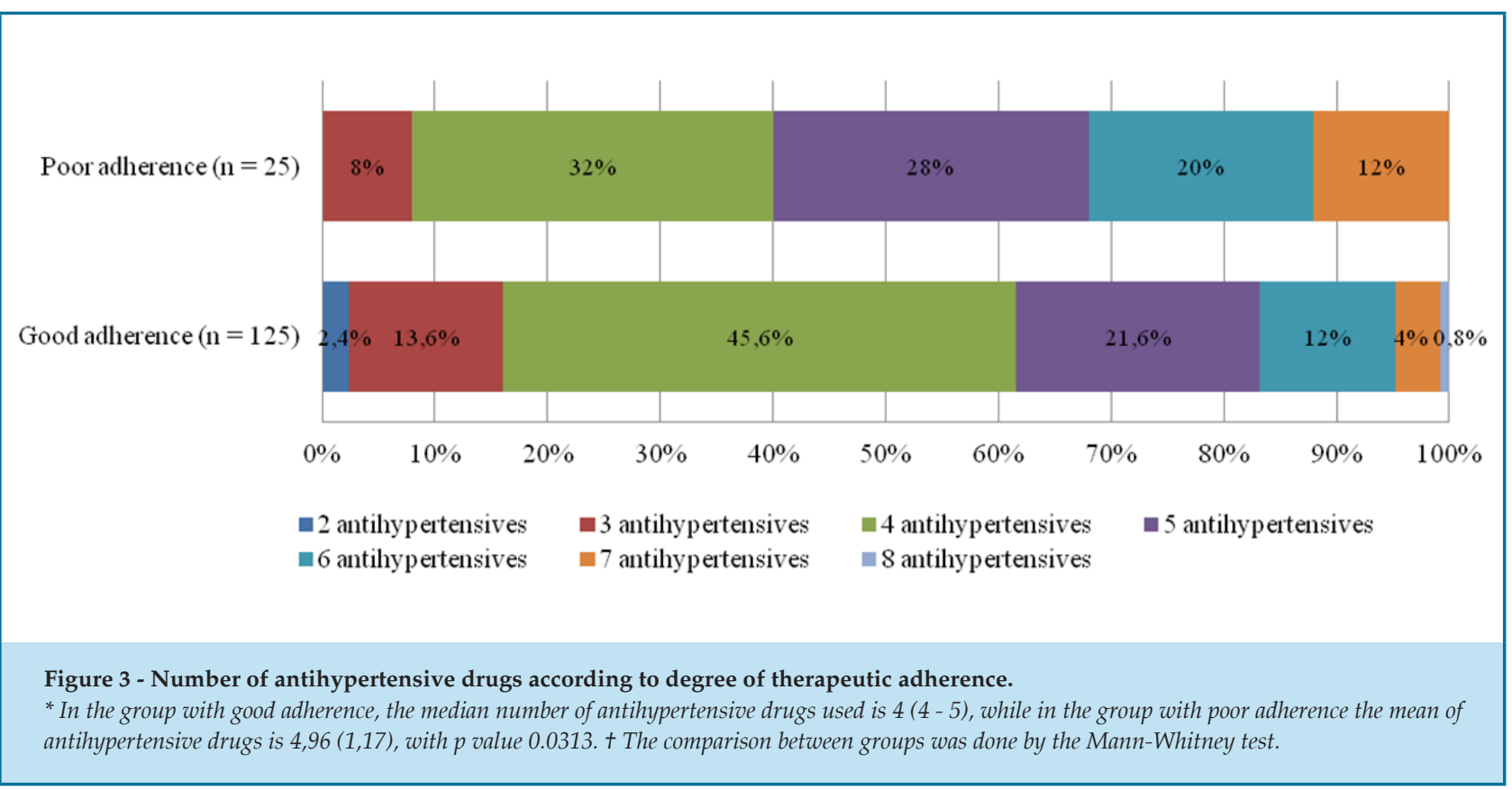


follow-up..$^{5,10}$ All of these variables were analyzed. However, there was no statistical significance for any of them as contributors to poor adherence, possibly because it is a cohort population with high cardiovascular risk and poorly diversified ethnic profile.

The number of medications used may also have an impact on the degree of therapeutic adherence, ${ }^{5,10}$ which was confirmed in this study, since the group with poor adherence used a significantly higher number of antihypertensive drugs. It is important to consider this finding when making prescriptions, as the use of tablets with drug combinations may be an effective strategy to improve adherence. In addition, emphasizing the need to change lifestyle, consider switching the drug class or increasing the dose of some drug already used - always considering the risk of developing adverse effects when increasing the dose - may be better for therapeutic adherence than just adding more drugs to the patient's prescription.

There is evidence that poor therapeutic adherence is one of the main obstacles to pressure control. ${ }^{3,4,10,12}$ Therefore, patients with greater adherence tend to have lower pressure levels and greater BP reductions. ${ }^{11,12}$ In this sample, it was found that, regardless of the degree of adherence, most individuals did not have good BP control, with no statistical difference between the groups. Even so, an expected trend can be identified in the groups: of the individuals with controlled BP, most are part of the group that has good adherence, whereas of the individuals with uncontrolled BP, most are part of the group with poor adherence.

The absence of BP control in a large part of the population with poor adherence is expected..$^{3,4,10}$ However, in the group with good adherence, poor BP control was not expected. This can be explained by the low sensitivity of the Morisky test - only $43.6 \%$ which, despite being the most used method in Brazil to quantify adherence to antihypertensive therapy, facilitating the comparison between studies, may not be the ideal one. ${ }^{4,10}$ Thus, considering that patients with poor BP control have lower chances of having good therapeutic adherence, ${ }^{12}$ patients classified by Morisky test as having good adherence could possibly have poor adherence. Therefore, Morisky test cannot be considered efficient to relate BP control to the patients' posture as for taking their medications. ${ }^{12}$ In addition, the high rate of poor BP control in the group with good adherence can also be explained by the fact that it is a group of individuals already very severe, so the pathophysiology of the disease itself makes it difficult to control BP levels even in those patients who follow the therapeutic scheme appropriately. Thus, it remains controversial in this population whether the adequate use of medications is as determining for the control of $\mathrm{BP}$ in severe patients as it would be for patients with nonresistant SAH.

Not only is adherence important for controlling BP levels, but also the use of appropriate therapy - to the extent that, when inappropriate, it is indicative of pseudoresistance. In this sample, most of the patients used the combination of thiazide diuretic + ACE/ARB $+\mathrm{CCB}$, but a considerable percentage did not use this combination, which is worrying, as they are patients with severe $\mathrm{SAH}$ seen at a reference clinic.

Correct diagnosis of $\mathrm{RH}$ requires verification of adherence to treatment, ${ }^{11}$ since poor adherence with uncontrolled BP will lead to unnecessary tests and modifications of prescription. ${ }^{10}$ Despite the difficulty of controlling all causes of pseudoresistance to exclude cases of apparent $\mathrm{RH}^{2}$, the presence of pseudoresistance can be estimated. In this sample, patients with pseudoresistant $\mathrm{SAH}$ were identified from the evaluation of therapeutic adherence by the Morisky test, the therapeutic regimen used and ABPM. An estimated $28 \%$ of pseudoresistance in an outpatient clinic specialized in severe hypertension raises some questions about the way these patients are being monitored and the criteria for staying in a tertiary care service.

Therefore, considering the results found, adherence to antihypertensive therapy can be increased by instructing patients on the importance of taking medications ensuring that they have understood it - and by drawing strategies with the patients and their family to help them remember to take the medications properly. In addition, investigating possible adverse effects and discomfort with the use of medications is critical in order to, if necessary, change the drug or make dose adjustments to prevent the patient from discontinuing the medication on their own. Prescription of combined drugs in a single tablet also appears to be an effective strategy to improve adherence, as well as the judgment of the need to introduce another drug into the prescription, as this may compromise adherence to the entire prescription.

The lack of data on pill counts or evaluation of serum levels of drugs brings a limitation to data analysis, especially considering that the Morisky test presents a sensitivity of only $40.3 \%$ for the evaluation of therapeutic adherence. Within the sample, no cases 
of secondary hypertension were investigated, which is also a limitation of the study.

Comparison of studies of patients with $\mathrm{RH}$ is difficult due to the small number of studies that consider only this subgroup of hypertensive patients, as well as those that consider therapeutic adherence to evaluate the diagnosis of $\mathrm{RH}$ and its differentiation from pseudoresistance. ${ }^{10,11}$ Considering adherence to the diagnosis of $\mathrm{RH}$ is fundamental, since poor adherence to therapy and $\mathrm{RH}$ do not coexist, because it must have good adherence to define SAH as resistant. ${ }^{10}$ Thus, further studies focusing on this specific group of patients with $\mathrm{RH}$ are needed to improve therapeutic management, blood pressure control and clinical outcomes.

\section{Conclusion}

The majority of patients included in the study showed good therapeutic adherence according to the Morisky scale. An analysis of the factors that could influence adherence, only the number of antihypertensive drugs had a statistically significant influence, while the epidemiological, anthropometric and clinical characteristics were statistically insignificant. The estimated prevalence of pseudoresistance was approximately 20\%, considering the Morisky test, the therapeutic regimen used and ABPM.

\section{Authors' contributions}

Research creation and design: Araújo LBS. Data acquisition: Araújo LBS. Data analysis and interpretation:
Araújo LBS. Statistical analysis: Araújo LBS. Manuscript writing: Araújo LBS. Critical revision of the manuscript for intellectual content: Araújo LBS and Aras Junior R. Supervision/as the major investigator: Araújo LBS. and Aras Junior R.

\section{Potential Conflicts of Interest}

No potential conflicts of interest relevant to this article were reported.

\section{Sources of Funding}

There were no external funding sources for this study.

\section{Study Association}

This study is not associated with any thesis or dissertation work.

\section{Ethics approval and consent to participate}

This study was approved by the Ethics Committee of Hospital Ana Nery under protocol number 138371. All the procedures in this study were in accordance with the 1975 Helsinki Declaration, updated in 2013. Informed consent was obtained from all participants included in the study.

\section{References}

1. Malachias MVB, Souza WKSB, Plavnik FL, Rodrigues CIS, Brandão AA, Neves MFT, et al. 7a Diretriz Brasileira de Hipertensão Arterial. Arq Bras Cardiol. 2016;107(3Suppl):1-83.

2. Judd E, Calhoun DA. Apparent and true resistant hypertension: definition, prevalence and outcomes. J Hum Hypertens. 2014;28(8):463-8.

3. Calhoun DA, Jones D, Textor S, Goff DC, Murphy TP, Toto RD, et al. Resistant Hypertension: Diagnosis, Evaluation, and Treatment. Circulation. 2008;117(25):510-26.

4. Ben AJ, Neumann CR, Mengue SS. Teste de Morisky-Green e Brief Medication Questionnaire para avaliar adesão a medicamentos. Rev Saúde Pública. 2012;46(2):279-89.

5. Gusmão JL, Ginani FG, Silva GV, Ortega KC, Mion Jr D. Adesão ao tratamento em hipertensão arterial sistólica isolada. Rev Bras Hipertens. 2009;16(1):38-43.

6. Morisky DE, Green LW, Levine DM. Concurrent and predictive validity of a self-reported measure of medication adherence. Med Care. 1986;24(1):67-74.

7. Ulbrich EM, Mantovani MF. Fatores preditivos para complicações em pessoas com hipertensão arterial sistêmica e ações para o gerencimento de cuidados da enfermagem na atenção primária. [tese]. Curitiba: Universidade Federal do Paraná; 2015.

8. Krieger EM, Drager LF, Giorgi DM, Pereira AC, Barreto Filho JA, Nogueira AR, et al. Spironolactone Versus Clonidine as a FourthDrug Therapy for Resistant Hypertension: The ReHOT Randomized Study (Resistant Hypertension Optimal Treatment). Hypertension. 2018;71(4):681-90.

9. Garg JP, Elliott WJ, Folker A, Izhar M, Black HR. Resistant Hypertension Revisited: A Comparison of Two University-Based Cohorts. Am J Hypertens. 2005;18(5Pt 1):619-26. 
10. Jesus NS, Nogueira AR, Pachu CO, Luiz RR, Oliveira GMM. Blood Pressure Treatment Adherence and Control after Participation in the ReHOT. Arq Bras Cardiol. 2016;107(5):437-45.

11. Bloch KV, Melo AN, Nogueira AR. Prevalência da adesão ao tratamento anti-hipertensivo em hipertensos resistentes e validação de três métodos indiretos de avaliação da adesão. Cad Saúde Pública. Dez 2008;24(12):2979-84

12 Prado JC Jr, Kupek E, Mion D Jr. Validity of four indirect methods to measure adherence in primary care hypertensives. J Hum Hypertens. 2007;21(7):579-84 